\title{
Two modifiers of sperm transport within the Fallopian tube of the rat
}

\author{
K. M. Sultan* and J. M. Bedford ${ }^{\dagger}$ \\ The Centre for Reproductive Medicine and Infertility, Cornell Medical Center, New York Hospital, \\ New York, NY 10021, USA
}

\begin{abstract}
In several mammals studied, ovulation appears to stimulate coordinated translocation of a few potential fertilizing spermatozoa to the ampulla from the caudal isthmus of the Fallopian tube. The present experiments demonstrate that, in the rat, this movement is regulated to a considerable degree within each duct by the ipsilateral ovary. Unilateral ovariectomy had no effect on ipsilateral sperm transport into the uterus, but this brought a unilateral quenching of sperm transport to the ampulla of the oviduct, from which spermatozoa were often totally or almost absent. This suppression was always complete on the ipsilateral side in unilaterally ovariectomized females anaesthetized with sodium pentobarbital soon after ovulation, and was evident bilaterally also at a highly significant level among intact females that were anaesthetized in this way. Unilateral ovariectomy and sodium barbital anaesthesia could provide experimental situations through which to decipher the mechanisms of normal sperm transport in the Fallopian tube.
\end{abstract}

\section{Introduction}

In mammals, the delivery of spermatozoa to the site of fertilization has proven to be an intriguingly complex process. In some species, only very few vaginal spermatozoa select themselves as further 'players' in passage through the canal of a cervix filled with receptive mucus. In others, most ejaculated spermatozoa pass into the uterus, immediately in pigs, dogs and horses, or within a few minutes after vaginal deposition in muroid rodents (see Drobnis and Overstreet, 1992). This initial phase is promoted in some groups by penile locking (for example dogs, certain insectivores and some rodents), or by deposition of a vaginal plug (for example certain rodents, insectivores, and primates).

Where spermatozoa enter the uterus in bulk, an optimal population is established in the posterior oviduct within an hour (rat: Leonard, 1950; pig, Hunter, 1981). In rats, the eggs may often all be fertilized when uterine spermatozoa are removed only $15 \mathrm{~min}$ after ejaculation, by flushing with distilled water and uterine ligation $(\mathrm{K}$. Wu and J. M. Bedford, unpublished). Where the cervix modulates the number of spermatozoa reaching the uterus, establishment of an optimal tubal population requires perhaps $6 \mathrm{~h}$ or longer (sheep: Hunter et al., 1980; cattle: Hunter and Wilmut, 1982). Whatever the pattern of the initial phase, this generally establishes a reservoir of a few thousand spermatozoa within the lumen of the posterior isthmus. Sperm motility there may be subdued by a mucus or a suppressive ionic milieu or by both factors (see Drobnis and Overstreet, 1992), and with maintenance of a viable subpopulation of spermatozoa possibly dependent on adherence of spermatozoa to the isthmic epithelium (see

*Present address: New York Fertility Institute, 1016 Fifth Avenue, New York, NY 10028, USA.

${ }^{+}$Correspondence: Box 30, 1300 York Avenue, New York, NY 10021, USA Received 17 April 1996.
Lefebvre and Suarez, 1996). In some mammals, the tubal sperm reservoir is housed before ovulation within special crypts located in the isthmus (didelphid and dasyurid marsupials: Rodger and Bedford, 1982; Breed et al., 1989; Bedford and Breed, 1994; crocidurine shrews: J. M. Bedford, T. Mori, S. Oda, H. Mover-Lev and D. M. Phillips, unpublished) or in the ampulla (the least shrew. Cryptotis parva: J. M. Bedford, O. B. Mock and D. M. Phillips, unpublished). The human may prove to be another special case in that spermatozoa appear to be distributed throughout the Fallopian tubes without regard to the time of ovulation (Williams et al., 1993).

The final stage, transport of a few potentially fertilizing spermatozoa to the ampulla, is notable for its coordination by ovulation and for its parsimony. Spermatozoa begin to reach the ampulla only at or some hours after ovulation, and in numbers that hardly match the number of eggs (Harper, 1973; Cummins and Yanagimachi, 1982; see Drobnis and Overstreet, 1992). As typified by the pig (Hancock, 1961) and rat (Bedford and Kim, 1993), only after fertilization is completed does the number of spermatozoa in the ampulla gradually increase significantly beyond that.

What determines the final translation of a small fertilizing subpopulation from the isthmus to the ampulla? It has been suggested that completion of capacitation and some change in the physical character and ionic composition of isthmic tubal content may activate and free some viable spermatozoa adhering to the isthmic epithelium (Smith and Yanagimachi, 1991; Lefebvre and Suarez, 1996). Hunter (1995) in particular has considered how the ovulating follicle(s) may stimulate this translocation - whether via direct intraluminal effects of ovulation products, or through follicular hormones delivered systemically or concentrated ipsilaterally through countercurrent exchange or by both processes (Hunter et al., 1983).

In the present study with rats, prior removal of one ovary allowed direct examination of its ipsilateral influence on sperm 
transport to the swollen portion of the ampulla which contains the fertilizing cohort. At the same time, a chance observation has shown that anaesthesia induced by sodium pentobarbital, by itself, can significantly depress the establishment of an ampullary sperm population.

\section{Materials and Methods}

\section{Animals and treatments}

Male (400-450 g) and female (180 g) Sprague-Dawley rats were obtained from Charles River Laboratories, and were maintained on Purina rat chow and water ad libitum. The animals were kept under a $12 \mathrm{~h}$ light:12 h dark cycle, with lights off at $18.00 \mathrm{~h}$. The experimental protocol was approved by the institutional animal care committee.

\section{Experiment 1: effects of unilateral ovariectomy}

Females were anaesthetized with sodium pentobarbital $\left(60 \mathrm{mg} \mathrm{kg}^{-1}\right.$ i.p.: Nembutal: Abbott, North Chicago, IL), then either the left or right ovary was removed through a flank incision and the pedicle was tied with $7 \times 0$ silk. A similar flank laparotomy was also performed on the contralateral side, together with a comparable slit in the ovarian bursa, but the ovary was left in place. Surgery was performed under a Zeiss operating microscope, care being taken to avoid the Fallopian tube, to make a minimal slit in the ovarian bursa, and with minimal needle diathermy to maintain a bloodless field. After successful surgery, females were left for at least 3 weeks before use. In three unilaterally ovariectomized animals, both oviducts were dissected, straightened, and their respective lengths measured. Three other such females were used to compare numbers of spermatozoa in the contralateral uterus in the pre-dawn hours after mating. Bilateral uterine counts were also obtained from three females with retained uterine spermatozoa in the unilaterally ovariectomized group given sodium pentobarbital.

For mating, an oestrous female selected according to her vaginal smear was placed at about $19.00 \mathrm{~h}$ with one of seven males of proven fertility. No male was used more than once every 4 days, and the use distribution was similar for each male throughout the study, i.e. there was no bias towards a particular male in any one group. The pairs were observed for coital mounting, and then left overnight in red light. At about $08.30 \mathrm{~h}$ on the next day, each female was checked for vaginal spermatozoa, then killed with $\mathrm{CO}_{2}$ at different times from 11.00 to $17.00 \mathrm{~h}$. After a mid-line laparotomy, the tubal ampulla on the intact and ovariectomized sides was clearly identified under a dissecting microscope, and the region was excised without loss of fluid content using microscissors and watchmakers' forceps. Each discreet swollen ampulla (Fig. 1) was immediately placed on a slide, trimmed of mesosalpinx and then placed on a wax-spot slide, and the whole content of the ampulla alone, including ova in cumulus on the intact side, was stripped with watchmakers' forceps into a small drop of Hanks balanced salt solution, sometimes containing $0.1 \%(\mathrm{w} / \mathrm{v})$ hyaluronidase (Sigma, St Louis, MO). The stripping process, often repeated, served to remove most epithelium and essen-

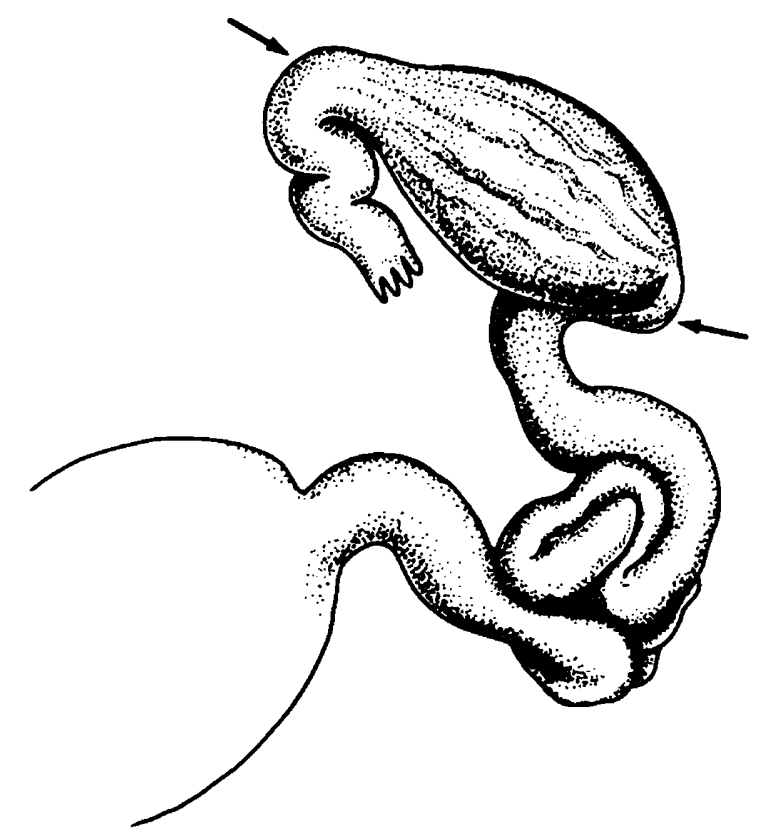

Fig. 1. A rat Fallopian tube partly uncoiled by dissection on the day of ovulation, to show the form of the locally distended ampullary region (arrows), from which spermatozoa and eggs were recovered.

tially left the ampulla as a serosal shell. The stripped ampullary shell was discarded, a cover glass was pressed onto the wax spots, anchoring eggs in cumulus oophorus, and the slide was examined under a phase contrast microscope. By methodical scanning immediate counts were made of the total number of spermatozoa associated with eggs plus cumulus when present, and in the fluid and epithelial debris, and the fertilization status of any eggs was noted.

\section{Experiment 2: effects of post-ovulatory anaesthesia}

Oestrous females (including 11 females unilaterally ovariectomized as above) were first paired with a male at about $19.00 \mathrm{~h}$. Very early on the next day, at $03.30-04.00 \mathrm{~h}$, the vagina was checked for spermatozoa. If spermatozoa were detected females were then anaesthetized, at $04.10-04.50 \mathrm{~h}$ (1-3 h after ovulation), with sodium pentobarbital i.p. (65$70 \mathrm{mg} \mathrm{kg}^{-1}$ ). Control females were injected similarly i.p. at the same early time, but with $0.3 \mathrm{ml} \mathrm{10 \%} \mathrm{ethyl} \mathrm{alcohol} \mathrm{(the} \mathrm{vehicle}$ in the Nembutal formulation). The animals injected with sodium pentobarbital remained anaesthetized until they were killed at either $10.30-11.00 \mathrm{~h}$ or $13.30-14.15 \mathrm{~h}$. Before that, between 09.00 and $10.00 \mathrm{~h}$ the level of anaesthesia was monitored according to the response to foot pressure. Where this was light in four animals to be killed in the early afternoon, for conformity these then received a supplementary i.p. injection of 17-18 mg sodium pentobarbital to maintain anaesthesia. Immediately after death, the uteri were examined for spermatozoa, and tubal ampullae were removed. After extrusion of ampullary contents as above, spermatozoa in the cumulus and in the fluid, the fertilization status of eggs, and the state of the cumulus were recorded. 
Table 1. Effects of unilateral ovariectomy on numbers of spermatozoa in the ipsilateral ampulla of the Fallopian tube of the rat after natural mating

\begin{tabular}{|c|c|c|c|c|c|c|}
\hline \multirow{2}{*}{$\begin{array}{c}\text { Time of } \\
\text { examination } \\
\text { (h) }\end{array}$} & \multirow[b]{2}{*}{$\begin{array}{l}\text { Number of } \\
\text { females }\end{array}$} & \multicolumn{2}{|c|}{$\begin{array}{c}\text { Mean number of } \\
\text { spermatozoa in ampulla }\end{array}$} & \multirow[b]{2}{*}{$\begin{array}{l}\text { Cumuli } \\
\text { intact }\end{array}$} & \multirow{2}{*}{$\begin{array}{c}\text { Mean number } \\
\text { of eggs } \\
\text { (range) }\end{array}$} & \multirow[b]{2}{*}{$\begin{array}{l}\text { Percentage } \\
\text { fertilized }\end{array}$} \\
\hline & & $\begin{array}{c}\text { Ovex. side } \\
\text { (range) }\end{array}$ & $\begin{array}{c}\text { Intact side } \\
\text { (range) }\end{array}$ & & & \\
\hline $11.00-12.00$ & 7 & $\begin{array}{r}6.0 \\
(0-32)\end{array}$ & $\begin{array}{r}58.5 \\
(8-149)\end{array}$ & $7 / 7$ & $\begin{array}{c}14.2 \\
(10-20)\end{array}$ & 71.7 \\
\hline $12.00-13.00$ & 5 & $\begin{array}{c}13.4 \\
(0-55)\end{array}$ & $\begin{array}{r}117.6 \\
(25-230)\end{array}$ & $3 / 5$ & $\begin{array}{c}14.2 \\
(11-18)\end{array}$ & 95.7 \\
\hline $13.00-14.00$ & 6 & $\begin{array}{c}23.0 \\
(0-101)\end{array}$ & $\begin{array}{r}139.8 \\
(38-296)\end{array}$ & $5 / 6$ & $\begin{array}{l}12.5 \\
(5-15)\end{array}$ & 96.0 \\
\hline $14.00-15.00$ & 7 & $\begin{array}{r}35.6 \\
(0-98)\end{array}$ & $\begin{array}{c}256.0 \\
(45->1000)\end{array}$ & $3 / 7$ & $\begin{array}{l}12.0 \\
(7-16)\end{array}$ & 96.4 \\
\hline $15.00-16.00$ & 4 & $\begin{array}{r}9.8 \\
(0-21)\end{array}$ & $\begin{array}{r}286.3 \\
(43-453)\end{array}$ & $2 / 4$ & $\begin{array}{c}9.75 \\
(8-11)\end{array}$ & 100.0 \\
\hline $16.00-17.00$ & 4 & $\begin{array}{r}26.0 \\
(0-93)\end{array}$ & $\begin{array}{l}70.5 \\
(40-98)\end{array}$ & $1 / 4$ & $\begin{array}{l}9.0 \\
(6-15)\end{array}$ & 100.0 \\
\hline
\end{tabular}

Ovex: ovariectomized.

\section{Statistical analysis}

The difference in the number of spermatozoa from the ampulla on the intact and ovariectomized sides was examined, (i) parametrically using the paired $t$ test with each individual acting as its own control, and (ii) non-parametrically using the 'sign test' and a sign rank test to assure thoroughness. The paired $t$ test was used to assess the differences in numbers of spermatozoa in the ampulla between the anaesthetized and control females.

\section{Results}

\section{Ipsilateral ovarian influence on sperm transport}

From three weeks after microsurgical removal of one ovary via a slit in its bursa, there were no adhesions involving the Fallopian tube. With the exception of a few females among those examined after $14.00 \mathrm{~h}$, there was a localized distension of the ampulla on the intact side on the day of ovulation (Fig. I), and the ampulla was similarly distended with fluid on the ovariectomized side. On the intact side, stripping of the excised ampulla revealed eggs, either within or free of cumulus according to the time and the individual, together with spermatozoa the relatively large size of which readily allowed accurate counting. Checks of the ovarian bursa revealed no more than the occasional spermatozoon within it. Fluid from the ampulla on the ovariectomized side contained only epithelial debris and on many occasions a few spermatozoa. Fallopian tubes from the intact and experimental sides of three nonmated females taken more than four weeks after unilateral ovariectomy and straightened by dissection revealed no difference in their respective lengths $(1.7-1.8 \mathrm{~cm})$. As another monitor, three unilaterally ovariectomized females paired with males and later killed at about $04.00 \mathrm{~h}$ had comparable numbers of spermatozoa in each uterine horn (range $65-120 \times 10^{6}$ per side), as did three anaesthetized females with retained uterine spermatozoa at 13.30-14.15 h. Three mated females in which ovulation had failed to occur (by 11.25, 13.50 and $16.00 \mathrm{~h}$, respectively) were excluded from the results, as were two others in which fluid distension of the ovariectomized oviduct had extended to more than the ampulla per se.

As shown in Table 1, there were significantly fewer spermatozoa in the ampulla with no ipsilateral ovary than in the intact side ( $t$ test, $P<0.0005$; signed rank test, $P<0.0001$ ). In fact, there were no spermatozoa in the ampulla of the ovariectomized side in 4 of 7 females in the $11.00-12.00 \mathrm{~h}$ group, nor in some females examined later, and many other counts were close to zero. Exceptions to this disparity included a female examined at $14.30 \mathrm{~h}$ and another at $16.00 \mathrm{~h}$ (both with fertilized eggs), in which the intact and ovariectomized ampullae each had $\geq 90$ spermatozoa. In other instances also, the absence of an ipsilateral ovary did not absolutely preclude sperm colonization of the ampulla, as can be seen from the ranges for each group. However, in the few animals in which the ovariectomized side had tens of spermatozoa, the intact side housed hundreds. Thus, there was virtually always a far greater number of spermatozoa within the ampulla on the intact side. As noted previously (Bedford and Kim, 1993), most ampullary spermatozoa were located within the cumulus, and were found in the fluid only after cumulus dispersal had occurred.

\section{Influence of sodium pentobarbital anaesthesia on tubal sperm transport}

This aspect was stimulated by unexpected results in exploratory experiments performed to study the effect on fertilization of $2 \%(\mathrm{v} / \mathrm{v})$ phosphate-buffered glutaraldehyde or culture medium instilled locally into one ovarian bursa of mated females soon after ovulation. In those, three mated females anaesthetized at $03.30-04.00 \mathrm{~h}$ with sodium pentobarbital 
Table 2. Effects of sodium pentobarbital given i.p. to intact mated rats at $04.00-05.00 \mathrm{~h}$ on numbers of spermatozoa subsequently in the ampulla of the Fallopian tube, and on the incidence and timing of fertilization

\begin{tabular}{|c|c|c|c|c|c|c|c|c|c|}
\hline Group & $\begin{array}{c}\text { Number of } \\
\text { females }\end{array}$ & $\begin{array}{c}\text { Time of } \\
\text { examination } \\
\text { (h) }\end{array}$ & $\begin{array}{c}\text { Mean number of } \\
\text { spermatozoa in } \\
\text { both ampullae } \\
\text { (range) }\end{array}$ & $\begin{array}{l}\text { Cumuli } \\
\text { intact }^{\circ}\end{array}$ & $\begin{array}{c}\text { Mean number } \\
\text { of eggs } \\
\text { (range) }\end{array}$ & $\begin{array}{l}\text { Percentage } \\
\text { fertilized } \\
\text { (range) }\end{array}$ & $\begin{array}{l}\text { Percentage } \\
\text { of large } \\
\text { pronuclei }\end{array}$ & $\begin{array}{l}\text { Percentage } \\
\text { of small } \\
\text { pronuclei }\end{array}$ & $\begin{array}{l}\text { Percentage } \\
\text { of swollen } \\
\text { sperm heads }\end{array}$ \\
\hline Experimental & 6 & $10.30-11.00$ & $\begin{array}{c}14.8 \\
(0-32)\end{array}$ & $12 / 12 \mathrm{C}$ & $\begin{array}{c}16.0 \\
(13-18)\end{array}$ & $\begin{array}{c}25.0 \\
(0-55)\end{array}$ & 0.0 & 38.2 & 71.8 \\
\hline Sham & 6 & 10.3011 .00 & $\begin{array}{c}121.2 \\
(20-343)\end{array}$ & $\begin{array}{l}8 / 12 \mathrm{C} \\
4 / 12 \mathrm{D}\end{array}$ & $\begin{array}{c}17.5 \\
(11-29)\end{array}$ & 100.0 & $2 . I$ & 68.3 & 29.6 \\
\hline Experimental & 14 & $13.30-14.15$ & $\begin{array}{c}40.9 \\
(0-152)\end{array}$ & $\begin{array}{r}26 / 28 \mathrm{C} \\
2 / 28 \mathrm{D}\end{array}$ & $\begin{array}{c}16.3 \\
(12-19)\end{array}$ & $\begin{array}{c}61.5 \\
(0-100)\end{array}$ & 0.0 & 35.0 & 65.0 \\
\hline Sham & 12 & $13.30-14.15$ & $\begin{array}{c}373.5 \\
(120-1272)\end{array}$ & $\begin{array}{r}4 / 24 \mathrm{C} \\
10 / 24 \mathrm{D} \\
10 / 24 \mathrm{~A}\end{array}$ & $\begin{array}{c}17.5 \\
(14-22)\end{array}$ & $\begin{array}{c}99.5 \\
(93-100)\end{array}$ & 97.4 & 2.6 & 0.0 \\
\hline
\end{tabular}

${ }^{a} \mathrm{C}$ : cumulus in the compact state seen after ovulation; $\mathrm{D}$ : loose cumulus beginning to disperse; A: cumulus absent.

Table 3. Numbers of spermatozoa in the ampulla and fertilization rates, at $13.30-14.15 \mathrm{~h}$, in mated unilaterally ovariectomized females previously given sodium pentobarbital i.p. at $04.00-05.00 \mathrm{~h}$

\begin{tabular}{|c|c|c|c|c|c|c|c|c|c|}
\hline \multirow[b]{2}{*}{ Group } & \multirow[b]{2}{*}{$\begin{array}{c}\text { Number of } \\
\text { females }\end{array}$} & \multicolumn{2}{|c|}{$\begin{array}{c}\text { Mean number of } \\
\text { spermatozoa in both ampullae }\end{array}$} & \multirow[b]{2}{*}{$\begin{array}{l}\text { Cumuli } \\
\text { intact }^{\text {a }}\end{array}$} & \multirow{2}{*}{$\begin{array}{c}\text { Mean number } \\
\text { of eggs } \\
\text { (range) }\end{array}$} & \multirow[b]{2}{*}{$\begin{array}{l}\text { Percentage } \\
\text { fertilized } \\
\text { (range) }\end{array}$} & \multirow[b]{2}{*}{$\begin{array}{c}\text { Percentage } \\
\text { of large } \\
\text { pronuclei }\end{array}$} & \multirow[b]{2}{*}{$\begin{array}{l}\text { Percentage } \\
\text { of small } \\
\text { pronuclei }\end{array}$} & \multirow[b]{2}{*}{$\begin{array}{l}\text { Percentage } \\
\text { of swollen } \\
\text { sperm heads }\end{array}$} \\
\hline & & $\begin{array}{c}\text { Ovex. side } \\
\text { (range) }\end{array}$ & $\begin{array}{l}\text { Intact side } \\
\text { (range) }\end{array}$ & & & & & & \\
\hline Experimental & 5 & 0.0 & $\begin{array}{r}15.6 \\
(0-35)\end{array}$ & $5 / 5(\mathrm{C})$ & $\begin{array}{l}12.8 \\
(4-18)\end{array}$ & 31.3 & 0.0 & 18.9 & 80.1 \\
\hline Sham & 6 & $\begin{array}{c}43.4 \\
(2-101)\end{array}$ & $\begin{array}{c}303.2 \\
(60-1018)\end{array}$ & $\begin{array}{l}2 / 6(\mathrm{C}) \\
4 / 6(\mathrm{D})\end{array}$ & $\begin{array}{c}14.3 \\
(12-16)\end{array}$ & 96.5 & 80.1 & 16.3 & 3.6 \\
\hline
\end{tabular}

${ }^{\mathrm{a}} \mathrm{C}$ : compact inner cumulus; D: dispersing cumulus.

Ovex: ovariectomized.

were subjected to unilateral flank laparotomy and injection of about $0.05 \mathrm{ml}$ glutaraldehyde into one ovarian bursa. When examined later at 13.30-14.15 h, no ampullary eggs were penetrated on either the experimental or undisturbed control side, and there were no ampullary spermatozoa other than three found in one cumulus. When only Hanks culture medium was injected similarly at about $04.00 \mathrm{~h}$ into one bursa in two further females, by $13.30-14.15 \mathrm{~h}$ only 9 of 25 eggs were penetrated, the state of the fertilizing sperm head/male pronucleus indicated that penetration was very recent (delayed), and there were totals of only 17 and 44 spermatozoa in their respective ampullae. Thus, whether glutaraldehyde or culture medium were injected into one bursa soon after ovulation, sperm colonization of the ampulla and fertilization were totally or significantly suppressed later on the experimental side and, unexpectedly, on the undisturbed contralateral side as well. Further experiments, summarized in Tables 2 and 3, established that this suppression could be elicited, to a large extent, merely by induction of anaesthesia with sodium pentobarbital soon after ovulation.

There was no significant effect of the post-ovulatory injection regimen alone, including handling. Females given about $0.3 \mathrm{ml} \mathrm{10} \%$ alcohol i.p. (the vehicle for Nembutal) displayed rates of fertilization and pronuclear development, as well as cumulus dispersal patterns and numbers of spermatozoa in the ampulla (Table 2), similar to those on the intact side in unilaterally ovariectomized females (Table 1), and to those in a previous study of normal females (Bedford and Kim, 1993). By contrast, the number of spermatozoa in the ampulla of anaesthetized females was very much lower $(P<0.001)$ than that in sham-injected controls at 10.30-11.00 h and at 13.30-14.15 h, and the fertilization rates compared poorly with those in similarly timed controls. For example, after mating no eggs were fertilized by $13.30-14.15 \mathrm{~h}$ in 4 of 13 anaesthetized females, compared with the 100\% fertilization established with these same males by $11.00 \mathrm{~h}$ in sham-injected controls. An examination of Table 2 shows associated differences as well in the developmental stage of fertilized eggs and the cumulus around them, which tended to be more dispersed in the non-anaesthetized females. On the basis of swelling sperm heads or pronuclear development, it is clear that sperm penetration had generally occurred earlier in the sham-injected females.

Sodium pentobarbital anaesthesia exaggerated further the suppressive effects of unilateral ovariectomy on sperm transport to the ampulla (Table 3). There were no spermatozoa in 
the ampulla on the ovariectomized side in anaesthetized animals, compared with a mean of 43 in non-anaesthetized controls, and a fertilization rate of only $31 \%$ (versus $96.5 \%$ in the latter), with the surfeit of swelling sperm heads and compact cumulus as an indication that gamete interaction in most of these few had been delayed.

In addition to suppressive effects on tubal transport of spermatozoa, sodium pentobarbital anaesthesia tended to delay the normal early $(07.00-09.00 \mathrm{~h})$ loss of all uterine spermatozoa back into the vagina. Tens of millions of spermatozoa remained in both uterine horns of four of six anaesthetized females at 10.30-11.00 h, and in seven of 13 such females at 13.30-14.15 h, compared with one of six and one of 12 , respectively, among non-anaesthetized controls.

\section{Discussion}

The rat seems particularly useful in some respects as a model through which to explore the factors involved in sperm transport from the tubal isthmus to the site of fertilization in the ampulla. In this species, the distended ampulla presents as an anatomically discreet region where fertilization occurs, and the relatively large spermatozoa reaching it can easily be counted. This system was used in the present experiments and it provided the first direct evidence for many past inferences that it is the ipsilateral ovary which modulates the normal pattern of sperm transport to the ampulla. The presence of ipsilateral ovulating follicles is clearly not a sine qua non for this transition to occur in principle, since a few spermatozoa eventually reached the ampulla of the ovariectomized side in about $70 \%$ of all females. However, the lack of an ipsilateral ovary almost invariably brought a major and often a complete suppression of this shift. As late as $13.30 \mathrm{~h}$ - a time when all eggs have normally been fertilized, with many excess ampullary spermatozoa - on the ovariectomized side only $13 \%$ of the ampullae had more than ten spermatozoa; and there were none in $40 \%$, compared with a mean of 85 ampullary spermatozoa on the intact side up to this point.

The results reported here suggest that sodium pentobarbital anaesthesia exaggerates further the effects of, or synergizes with, unilateral ovariectomy in suppressing sperm transport to the ampulla. The clear inhibitory effect of sodium pentobarbital anaesthesia alone on sperm transport was unforeseen, and it remains to be shown how it acts in this regard. However, it was notable in all groups that such anaesthesia also often inhibited or delayed the sperm evacuation back into the vagina that is brought about normally in the early morning by reverse uterine peristalsis. Thus, sodium barbital may act in this respect by relaxing the smooth muscle of the female tract. Conceivably, such suppression of sperm transport to the ampulla might be exaggerated further if sodium pentobarbital were to be given at that time rather than about $3 \mathrm{~h}$ after ovulation. Since species differences are common at all points of conception in mammals, it cannot be assumed that barbiturates necessarily have similar effects in farm animals and primates, for example. From a practical standpoint it is useful to know for the rat at least that this suppression of tubal transport can happen, for instance where surgery and anaesthesia are contemplated as a facet of research on tubal physiology. Since methoxyflurane anaesthesia of hamsters did not seem to suppress oviduct contractility, as judged by ink droplet movements (Battalia and Yanagimachi, 1979), the effects reported here may relate to the use of barbiturates rather than to anaesthesia per se. However, it must be stressed that movement of spermatozoa does not necessarily parallel or reflect that of ink droplets in the oviduct.

What do these results reveal about the mechanisms that ensure the coordinated arrival of some spermatozoa in the ampulla, which, in several mammals and certainly in rats, seems to occur to a significant extent only after the arrival there of the cumulus-oocyte complex? On the basis of current ideas and experimental evidence from in vivo and in vitro studies, the transposition of a fertilizing population from the posterior isthmus may necessitate first some reactivation or enhancement of motility, and perhaps also release of spermatozoa from an adherent association with the isthmic epithelium. A second element may be the adovarian propulsive force brought by isthmic contraction. In analysing either aspect, the removal of an ovary does not discriminate between the products of ovulation entering the ampulla as a 'signal' (Harper, 1973), and direct ipsilateral effects on the isthmus of follicular steroids (Hunter et al., 1983), or other follicular secretion. With regard to the possible role of ovulation products, in the rat at least, follicular fluid components do not enter the ampulla (Shalgi et al., 1977). Moreover, the initial events of even bulk adovarian transport in hamsters seem to begin soon before ovulation (Battalia and Yanagimachi, 1979, 1980). Similarly, evidence from farm animals indicates that the initial release of spermatozoa from their isthmic arrest occurs before the entry of ovulation products into the ampulla (Hunter and Nichol, 1983; Hunter, 1984). Thus, it seems doubtful that the arrival of a cumulus-oocyte complex in the ampulla is the key stimulus for ascent of the few fertilizing spermatozoa from the tubal isthmus.

Possible candidates to consider as sole or co-effectors of the ipsilateral control via local routes include ovarian peptides, prostaglandins and steroid hormones. Prostaglandin synthesis rises on the day of pro-oestrus as a correlate of ovulating follicle development, but otherwise ovarian prostaglandin production does not change throughout the cycle in rats (Poyser and Scott, 1980). A probable candidate is change in the profile of hormones emanating from the ovary, especially the combination during pro-oestrus of falling oestrogen and a rising progesterone. The latter peaks in the rat about $6-8 \mathrm{~h}$ before ovulation, then falls to a basal value by the time of ovulation even in pseudopregnant females (Smith et al., 1975). Moreover, progesterone may be concentrated in the 'local' vasculature, and it may reduce oedema of the isthmus and so increase the patency of the lumen (Hunter, 1972; Hunter et al., 1983). In fact, oestrogen withdrawal with rising progesterone evokes the most efficient adovarian movement of ink droplets from the isthmus to ampulla in the hamster (Battalia and Yanagimachi, 1980). However, in that study such contractions were equally effective on the ovariectomized side, where sperm transport is significantly suppressed. Finally the observed translocation of ink droplets began within $3 \mathrm{~h}$ of progesterone administration, and required only a minute or so for completion. By contrast, spermatozoa do not begin to arrive in the ampulla of the rat until about $10 \mathrm{~h}$ after the progesterone peak. 
It may be that adovarian contractions of the duct wall have some role in engineering the transport of the larger populations of active spermatozoa that eventually present themselves in the ampulla after fertilization is complete. However, the lack of any simple conformity of sperm transport here with the reported movement of ink droplets in hamsters implies that much more than such contractions is involved in transposition of an initial fertilizing population to the ampulla. It may be that both unilateral ovariectomy and sodium pentobarbital, particularly when used together, constitute tools through which to explore further in vivo the precise mechanisms that govern this link in conception. Direct observation of how spermatozoa behave at different levels of the oviduct in these situations compared with controls, and how these treatments affect duct contractions, the isthmic environment and/or epithelial surface affinities for spermatozoa may help to explain the arrival of a few potentially fertilizing spermatozoa in the ampulla soon after ovulation.

The authors are grateful to $M$. Goldstein and to P. Lee who provided the microsurgical facilities for ovariectomy, and to F. H Moy, Director, Institute for Applied Statistics and Clinical Trials, Valhalla, NY for his help with the statistical calculations.

\section{References}

Battalia DE and Yanagimachi R (1979) Enhanced and coordinated movement of the hamster oviduct during the periovulatory period Journal of Reproduction and Fertility 56 515-520

Battalia DE and Yanagimachi R (1980) The change in oestrogen and progesterone levels triggers adovarian propulsive movement of the hamster oviduct Journal of Reproduction and Fertility $\mathbf{5 9} 243-247$

Bedford IM and Breed WG (1994) Regulated storage and subsequent transformation of spermatozoa in the Fallopian tubes of an Australian marsupial, Sminthopsis crassicaudata Biology of Reproduction 50 845-854

Bedford JM and Kim HH (1993) Cumulus oophorus as a sperm sequestering device Journal of Experimental Zoology 265 321-328

Breed WG, Leigh CM and Bennett JH (1989) Sperm morphology and storage in the female reproductive tract of the fat-tailed dunnart, Sminthopsis crassicandata (Marsupialia: Dasyuridae) Gamete Research 23 61-75

Cummins JM and Yanagimachi R (1982) Sperm-egg ratios and the site of the acrosome reaction during in vivo fertilization in the hamster Gamete Research 5 239-256

Drobnis EZ and Overstreet JW (1992) Natural history of mammalian spermatozoa in the female reproductive tract Oxford Reviews of Reproductive Biology $141-45$
Hancock JL (1961) Fertilization in the pig Journal of Reproduction and Fertility 2 307-331

Harper MJK (1973) Stimulation of sperm movement from the isthmus to the site of fertilization in the rabbit oviduct Biology of Reproduction 8 369-377

Hunter RHF (1972) Local action of progesterone leading to polyspermic fertilization in pigs Journal of Reproduction and Fertility 31 433-444

Hunter RHF (1981) Sperm transport and reservoirs in the pig oviduct in relation to the time of ovulation Journal of Reproduction and Fertility 63 109-117

Hunter RHF (1984) Pre-ovulatory arrest and peri-ovulatory redistribution of competent spermatozoa in the isthmus of the pig oviduct Journal of Reproduction and Fertilify $\mathbf{7 2}$ 203-211

Hunter RHF (1995) Ovarian endocrine control of sperm progression in the Fallopian tubes Oxford Reviews of Reproductive Biology 17 85-124

Hunter RHF and Nichol R (1983) Transport of spermatozoa in the sheep oviduct: preovulatory sequestering of cells in the caudal isthmus Journal of Experimental Zoology 228 121-128

Hunter RHF and Wilmut I (1982) The rate of functional sperm transport into the oviducts of mated cows Animal Reproduction Science 5 167-173

Hunter RHF, Nichol R and Crabtree SM (1980) Transport of spermatozoa in the ewe: timing of the establishment of a functional population in the oviduct Reproduction Nutrition Developpement 20 1869-1875

Hunter RHF, Cook B and Poyser NL (1983) Regulation of oviduct function in pigs by local transfer of ovarian steroids and prostaglandins: a mechanism to influence sperm transport European Journal of Obstetrics and Gynecology and Reproductive Biology 14 225-232

Lefebvre R and Suarez SS (1996) Effect of capacitation on bull sperm binding to homologous oviductal epithelium Biology of Reproduction 54 $575-582$

Leonard SL (1950) The reduction of uterine sperm and uterine fluid on fertilization of rat ova Anatomical Record 106 607-615

Poyser NL and Scott FM (1980) Prostaglandin and thromboxane production by the rat uterus and ovary in vitro during the oestrous cycle Journal of Reproduction and Fertility $6033-40$

Rodger JC and Bedford JM (1982) Induction of oestrus, recovery of gametes, and the timing of fertilization events in the opossum, Didelphis virginiana Journal of Reproduction and Fertility 64 159-169

Shalgi R, Kaplan R and Kraicer PF (1977) Proteins of follicular, bursal and ampullar fluids of rats Biology of Reproduction 17 333-338

Smith TT and Yanagimachi R (1991) Attachment and release of spermatozoa from the caudal isthmus of the hamster oviduct Journal of Reproduction and Fertility 91 567-573

Smith MS, Freeman ME and Neill JD (1975) The control of progesterone secretion during the estrous cycle and early pseudopregnancy in the rat: prolactin, gonadotropin and steroid levels associated with rescue of the corpus luteum of pseudopregnancy Endocrinology 96 219-226

Williams M, Hill CJ, Scudamore I, Dunphy B, Cooke ID and Barratt CLR (1993) Sperm numbers and distribution within the human Fallopian tube around ovulation Human Reproduction 8 2019-2026 